\title{
PEMBANGUNAN APLIKASI MANAJEMEN PENYIRAMAN RUMPUT TAMAN PLAYGROUND BERBASIS INTERNET OF THINGS
}

\author{
Komang Candra Brata ${ }^{* 1}$, Ginanjar Wisnu Ifan A. ${ }^{2}$, Adam Hendra Brata ${ }^{3}$ \\ 1,2,3 Fakultas Ilmu Komputer Universitas Brawijaya \\ Email: ${ }^{1}$ k.candra.brata@ub.ac.id, ${ }^{2}$ ifanagusti@student.ub.ac.id, ${ }^{3}$ adam@ub.ac.id \\ *Penulis Korespondensi
}

(Naskah masuk: 23 November 2020, diterima untuk diterbitkan: 22 Maret 2021)

\begin{abstract}
Abstrak
BUMDESMA Kecamatan Ngantang adalah Badan Usaha Milik Desa Bersama yang ada di Kecamatan Ngantang. Instansi ini adalah instansi baru yang memiliki usaha berupa playground. Dari awal pembukaan playground hingga terakhir yaitu bulan Juli 2019 pemasukan playground mengalami penurunan dikarenakan rusaknya rumput taman selama musim kemarau. Permasalahan yang dialami BUMDESMA adalah pemeliharaan rumput gajah mini untuk taman memerlukan metode penyiraman khusus namun BUMDESMA belum mampu menggunakan jasa penyiraman untuk menyiram taman playground. Dari permasalahan tersebut maka dikembangkan sistem penyiraman taman berbasis Internet of Things (IOT) untuk menekan biaya pengeluaran BUMDESMA. Sistem manajemen penyiraman taman menggunakan aplikasi yang ditanamkan pada perangkat Android untuk mengontrol sistem yang dibuat dan perangkat embedded untuk melakukan mekanisme penyiraman. Hasil pengujian blackbox menunjukan bahwa hasil uji $100 \%$ valid. Pengujian usability menunjukan nilai lebih dari kriteria minimum penelitian dengan nilai 72 yang berarti bahwa aplikasi dapat diterima oleh pengguna. Dari hasil pengujian efisiensi biaya menunjukan bahwa penggunaan sistem penyiraman dalam jangka panjang dapat mengurangi biaya pengeluaranan BUMDESMA dibanding penggunaan jasa penyiraman profesional.
\end{abstract}

Kata kunci: mobile aplication, Android, IoT, embedded, playground.

\section{AN IOT-BASED WATER MANAGEMENT SYSTEM FOR PLAYGROUND'S GRASS}

\begin{abstract}
BUMDESMA Kecamatan Ngantang is a Joint Village-Owned Enterprises located in Ngantang District, Malang, East Java. This is a new agency that has a playground as one of the core businesses. Along from the beginning of the playground operates until the end of July 2019, playground revenue has gradually decreased. This issue arises due to the bad condition of the grass on the playground causing local people are not willing to visit that place. The playground's grass requires special watering treatment but BUMDESMA is the lack of income so they cannot afford to pay the professional grass maintenance services to actively watering the playground grass. From these problems, We proposed an IOT based garden watering system to reduce BUMDESMA expenditure costs. The garden watering management system uses a mobile application as a user interface to control the system and embedded devices for the watering mechanism. Blackbox testing of the proposed system shows that all the functional requirements are $100 \%$ valid. Usability testing shows a value of 72 which is more than the minimum threshold of usability criterion means that the application is acceptable to users. The results of cost-efficiency testing show that the proposed water systems can reduce the cost when compared to using professional watering services.
\end{abstract}

Keywords: mobile application, Android, IoT, embedded, playground..

\section{PENDAHULUAN}

BUMDESMA Kecamatan Ngantang adalah singkatan dari Badan Usaha Milik Desa Bersama yang ada di Kecamatan Ngantang Kabupaten Malang. BUMDESMA adalah instansi baru gabungan dari 4 (empat) desa yang mengelilingi waduk Selorejo
Ngantang atau bisa disebut Kawasan. BUMDESMA memiliki salah satu usaha yaitu persewaan taman bermain atau playground. Menurut keterangan Wiwik selaku pengurus playground BUMDESMA Kecamatan Ngantang, selama lebih dari satu tahun mengelola playground pengunjung yang datang 
mengalami penurunan dari pembukaan sampai terakhir dikelola yaitu pada bulan Juli 2019 (Wiwik, 2019). Penyebabnya adalah kondisi taman yang memburuk. Hal tersebut dikarenakan pihak BUMDESMA kesulitan dalam menyiram rumput taman pada musim kemarau. Rumput taman yang digunakan adalah jenis rumput gajah mini dimana pemberian air secara berlebihan pada rumput gajah mini akan mengakibatkan akar tumbuh disekitar permukaan tanah atau pendek. Hal tersebut mengakibatkan tanaman tersebut mudah roboh atau lepas dari tanah karena akar kurang kuat. Sebaliknya jika air yang diberikan kurang atau tanaman sampai kekeringan maka akan mempengaruhi morfologi, fisiologi dan aktivitas tanaman (Juliantika \& Wicaksono, 2017). BUMDESMA yang masih memiliki pemasukan minim masih belum mampu memakai jasa penyiraman taman profesional.

Internet of Things (IoT) adalah sebuah sistem yang dapat dikontrol atau dioperasikan melalui jaringan internet. Dengan IoT objek tertentu bisa berkomunikasi lewat jaringan tanpa bantuan manusia atau komputer (Ray, 2018). IoT biasa diterapkan pada industri, wisata, rumah pintar dan lain-lain. Pada penelitian ini, akan dikembangkan $I o T$ dengan micro controller Raspberry Pi 3 Model $\mathrm{B}+$ dan Android untuk mengontrol sistem yang akan dikembangkan serta ditambahkan fitur voice recognition untuk mempermudah pengguna dalam menjalankan operasi yang ada pada sistem. Penggunaan Raspberry Pi 3 Model B+ dikarenakan micro controller ini sudah dilengkapi modul Wifi. Sedang penggunaan Android dikarenakan perangkat ini paling banyak digunakan oleh pengurus BUMDESMA Kecamatan Ngantang dan seluruh pengguna perangkat bergerak pada bulan Juli 2019 (statcounter, 2019).

BUMDESMA memerlukan sistem tersebut dengan tepat dan secepatnya. Maka untuk mengembangkan sistem manajemen penyiraman taman dalam penelitian ini, metode yang dipakai adalah Agile Development Methods. Metode ini memiliki kelebihan penyerahan produk secara cepat dan tepat waktu yaitu pada analisis dan desain. Tahap pengerjaan Agile Development Methods meliputi perencanaan, implementasi, tes perangkat lunak, dokumentasi, deployment, pemeliharaan (Abrahamsson, 2017).

Tujuan dikembangkan sistem ini adalah untuk mengurangi biaya perawatan taman playground BUMDESMA Kecamatan Ngantang dan juga taman lainya yang mengalami permasalahan yang sama. Karena apabila penyiraman tanaman terutama rumput tidak dilakukan secara rutin atau tidak sesuai kebutuhan tanaman maka dapat menyebabkan kematian tanaman tersebut.

\section{METODE PENELITIAN}

Penelitian ini mengadopsi metode Agile untuk dikerjakan pada beberapa tahap penelitian. Pengadopsian metode penelitian bisa dilihat pada
Gambar 1.

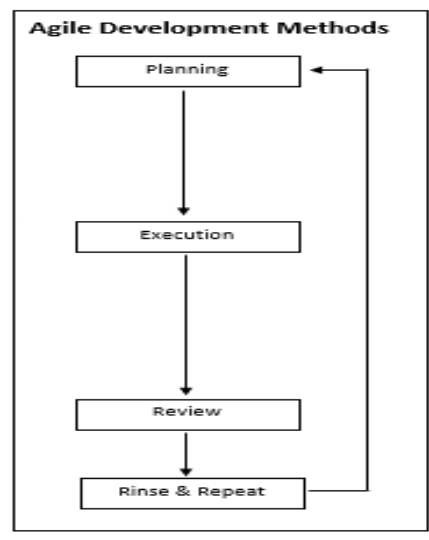

Gambar 1. Metodologi Penelitian

Pada penelitian ini dikembangkan sebuah sistem dengan 2 bagian yang berbeda. Bagian pertama adalah aplikasi mobile, yaitu bagian sistem yang bertatapan langsung dengan pengguna. Kedua adalah bagian perangkat embedded sistem, yaitu bagian sistem yang terhubung ke pompa air dan berguna untuk melakukan penyiraman. Gambaran dijelaskan pada Gambar 2.

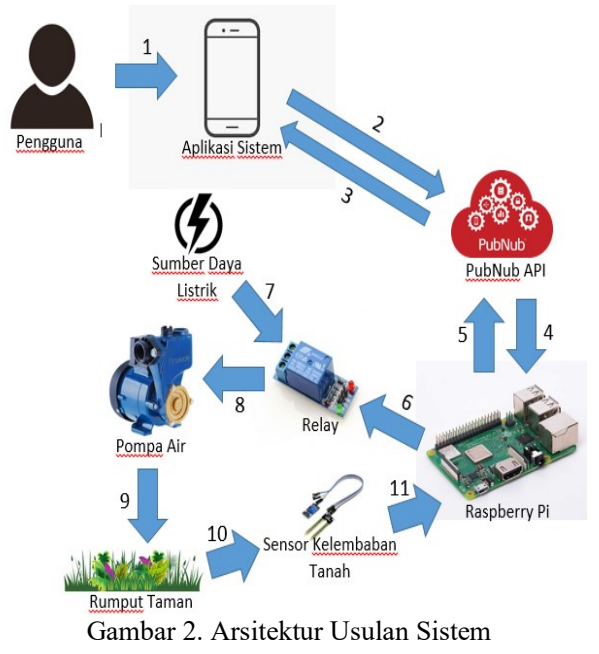

Input dimulai ketika pengguna memberi masukan berupa waktu dan intensitas penyiraman pada aplikasi sistem atau perintah melalui masukanan pesan suara pada aplikasi mobile. Setelah input dikenali oleh aplikasi selanjutnya aplikasi akan mengirim pesan perintah penyiraman, data waktu dan intensitas penyiraman ke PubNub API untuk diteruskan ke Raspberry Pi sebagai micro controller dari sistem. Ketika Raspberry Pi menerima data dari PubNub maka secara bersamaan Raspberry akan mengirim data status penyiraman ke PubNub lagi untuk mengupdate status di aplikasi mobile dan mengirimkan pesan ke relay untuk membuka atau menutup arus listrik yang dialirkan ke pompa air. Sensor kelembaban tanah dipasang pada taman untuk memantau kondisi tanah secara otomatis. Sensor ini terhubung ke Raspberry yang nantinya nilai sensor ini 
akan dijadikan sebagai indikator untuk menghentikan dan menyalakan pompa secara otomatis sesuai kondisi tanah. Nilai kelembabanya juga dapat dilihat pada antar muka aplikasi

Pada tahap analisis kebutuhan, dilakukan penggalian kebutuhan dan pembagian daftar kebutuhan ke beberapa iterasi untuk dikerjakan secara terpisah. Kebutuhan fungsional sistem yang dikembangkan bisa dilihat di Tabel 1. Dari daftar kebutuhan fungsional tersebut dibagi menjadi beberapa iterasi. Pada iterasi 1 terdapat 1 kebutuhan fungsional, yaitu kebutuhan fungsional dengan kode SRS_01. Pada iterasi 2 terdapat 4 kebutuhan fungsional tambahan, yaitu kebutuhan fungsional dengan kode SRS_02, SRS_03, SRS_05 dan SRS_06. Pada iterasi 3 terdapat 1 kebutuhan fungsional baru, yaitu kebutuhan fungsional dengan kode SRS_04.

Tabel 1. Spesifikasi Kebutuhan Fungsional Sistem

\begin{tabular}{|c|c|c|}
\hline $\begin{array}{l}\text { Kode } \\
\text { Fungsi }\end{array}$ & Nama Fungsi & Deskripsi \\
\hline \multirow[t]{2}{*}{ SRS-01 } & $\begin{array}{l}\text { Melakukan } \\
\text { penyiraman }\end{array}$ & $\begin{array}{l}\text { Sistem harus mampu untuk } \\
\text { melakukan penyiraman }\end{array}$ \\
\hline & manual & $\begin{array}{l}\text { secara langsung saat } \\
\text { pengguna ingin menyiram } \\
\text { taman saat itu juga. }\end{array}$ \\
\hline SRS-02 & $\begin{array}{l}\text { Melihat jadwal } \\
\text { penyiraman }\end{array}$ & $\begin{array}{l}\text { Sistem mampu untuk } \\
\text { melihat jadwal penyiraman } \\
\text { yang dilakukan secara } \\
\text { otomatis oleh sistem sesuai } \\
\text { dengan jadwal yang telah } \\
\text { ditentukan perminggu. }\end{array}$ \\
\hline SRS-03 & $\begin{array}{l}\text { Menerima } \\
\text { pemberitahuan }\end{array}$ & $\begin{array}{l}\text { Sistem memiliki fitur untuk } \\
\text { menampilkan pesan saat } \\
\text { kondisi tanah di playground } \\
\text { kering }\end{array}$ \\
\hline \multirow[t]{3}{*}{ SRS-04 } & $\begin{array}{l}\text { Melakukan } \\
\text { penyiraman }\end{array}$ & $\begin{array}{l}\text { Sistem memiliki fitur untuk } \\
\text { melakukan penyiraman }\end{array}$ \\
\hline & dengan perintah & menggunakan perintah \\
\hline & & $\begin{array}{l}\text { pemberitahuan bahwa tanah } \\
\text { sedang kering }\end{array}$ \\
\hline \multirow[t]{2}{*}{ SRS-05 } & $\begin{array}{l}\text { Menambah jadwal } \\
\text { penyiraman }\end{array}$ & $\begin{array}{l}\text { Sistem memiliki fitur untuk } \\
\text { menambah jadwal }\end{array}$ \\
\hline & & $\begin{array}{l}\text { penyiraman pada hari } \\
\text { tertentu }\end{array}$ \\
\hline \multirow[t]{2}{*}{ SRS-06 } & $\begin{array}{l}\text { Menghapus } \\
\text { jadwal } \\
\text { penyiraman }\end{array}$ & $\begin{array}{l}\text { Sistem harus menyediakan } \\
\text { fasilitas untuk menghapus } \\
\text { menambah }\end{array}$ \\
\hline & & $\begin{array}{l}\text { penyiraman pada hari } \\
\text { tertentu }\end{array}$ \\
\hline
\end{tabular}

Rancangan antarmuka aplikasi dapat dilihat pada Gambar 3. Dimana tujuan dari antarmukanya adalah memberikan tata letak perintah yang efisien dan mudah dipelajari agar penggua dapat dengan mudah menggunakan aplikasi untuk mengontrol perangkat embedded.

Kode program untuk front-end aplikasi diimplementasikan menggunakan Android Studio. Untuk perangkat embedded digunakan Java dengan IDE Netbeans. Untuk menjalankan kode Java pada perangkat Raspberry $\mathrm{Pi}$ digunakan Pi4J. Untuk komunikasi secara real-time antara aplikasi dengan perangkat embedded digunakan PubNub.

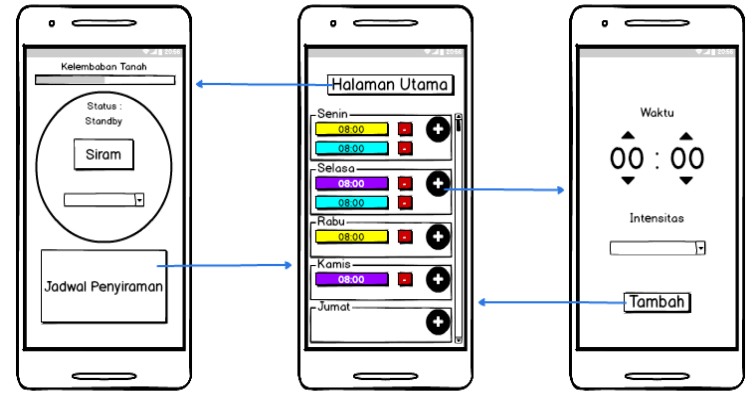

Gambar 3. Perancangan Antarmuka

\section{LANDASAN PUSTAKA}

Penelitian terdahulu yang berjudul "Perancangan Alat Penyiram Tanaman Otomatis pada Miniatur Greenhouse Berbasis IOT", oleh Astriana Rahma Putri, Suroso dan Nasron, dikembangkan sistem penyiraman tanaman pada greenhouse yang bisa diakses melalui internet, dengan menggunakan web server untuk mengontrolnya. Sebagai perangkat embedded sistem tersebut menggunakan Arduino, sensor suhu ruangan DHT11 dan pompa air. Untuk mengendalikan sistem kontrol penelitian tersebut menggunakan fuzzy logic. Tujuan dari penelitian tersebut adalah untuk membantu petani dalam efisiensi waktu, penghematan penggunaan air dan peningkatan kualitas dan kuantitas hasil green house (Putri, et al., 2019). Dalam penelitian tersebut digunakan Arduino sebagai micro controller, sedangkan pada penelitian yang dilakukan oleh penulis menggunakan Raspberry Pi. Perbedaan lainya yaitu penggunaan web server untuk mengontrol sistem, sedang pada penelitian ini digunakan perangkat Android untuk mengontrol sistem.

\subsection{Mobile Aplication}

Mobile Aplication atau aplikasi mobile yaitu aplikasi yang dijalankan di perangkat mobile. Kebanyakan aplikasi mobile saat ini berjalan pada perangkat smartphone. Aplikasi mobile memungkinkan dijalankan di dalam perangkat yang sederhanna seperti smartphone atau wearable, Penggunakan aplikasi mobile akan memungkinkan pengguna atau komputer melakukan pertukaran informasi atau aktifitas komputasi (Brata, 2019).

\subsection{Android}

Menurut Matsun, Android merupakan sistem operasi yang berkembang dalam sistem operasi smartphone pada saat ini. Android merupakan sistem operasi yang paling banyak digunakan pada perangkat smartphone pada saat ini (Matsun, et al., 2018).

\subsection{Voice Recognition}

Voice recognition, dalam bahasa Indonesia dikenal dengan pengenalan suara, merupakan 
pengembangan teknik dan sistem yang membuat komputer dapat mengenali masukan berbentuk ucapan. Teknologi ini mengubah suara yang diterima menjadi bentuk digital, setelah berbentuk digital masukan tersebut akan dicocokan dengan algoritma yang ditanamkan pada perangkat tertentu (Brata, 2020)

\subsection{Internet of Things (IoT)}

IoT adalah segala perangkat elektronik yang bisa dikendalikan dari jarak jauh melalui komunikasi internet. Menurut Yasha, IoT adalah konsep dimana objek tertentu mampu untuk bertukar data melalui jaringan tanpa bantuan komunikasi antar manusia atau manusia dengan perangkat komputer (Sethi, 2017).

\subsection{Raspberry Pi 3 Model B+}

Raspberry Pi 3 Model B+ merupakan mini komputer yang besarnya hanya seukuran KTP dan terjangkau untuk dibeli. Raspberry Pi 3 Model B+ bisa digunakan layaknya komputer pada umumnya seperti membuat dokumen, memuat video, musik, game, dan lainya. Raspberry PI 3 Model B+ terbentuk dari prosesor ARM11, GPU open GL ES 2.0, memori $512 \mathrm{mb}$, dan Port-port pendukung kegiatan komputasi lainya (Mulyanto \& Kushermanto, 2017). Penampakan fisik dari Rasberry Pi 3 Model B+ dapat dilihat pada Gambar 4. Dalam penggunaanya, Raspberry Pi memiliki susunan pin tersendiri apabila dijalankan menggunakan Pi4J. Gambar 5 menunjukkan susunan Pin yang digunakan dengan Pi4J.

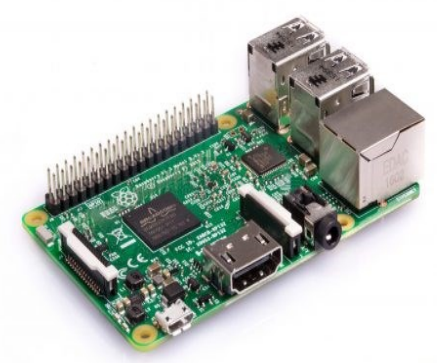

Gambar 4. Raspberry Pi 3 Model B+ yang digunakan dalam pengembangan

\subsection{Agile Development Methods}

Metode Agile merupan metode yang berguna untuk mengembangkan sistem perangkat lunak maupun perangkat keras. Agile Development Methods terdiri dari sekumpulan metodologi pengembangan perangkat lunak berbasis pengembangan iterasi (Stoica, 2016). Dalam proses pengerjaan perangkat lunak menggunakan metode Agile, pengguna akan selalu terlibat. Metode Agile dipilih dalam pengembangan proyek karena mudah dalam mengakomodasi perubahan (Pereira, et al., 2018).

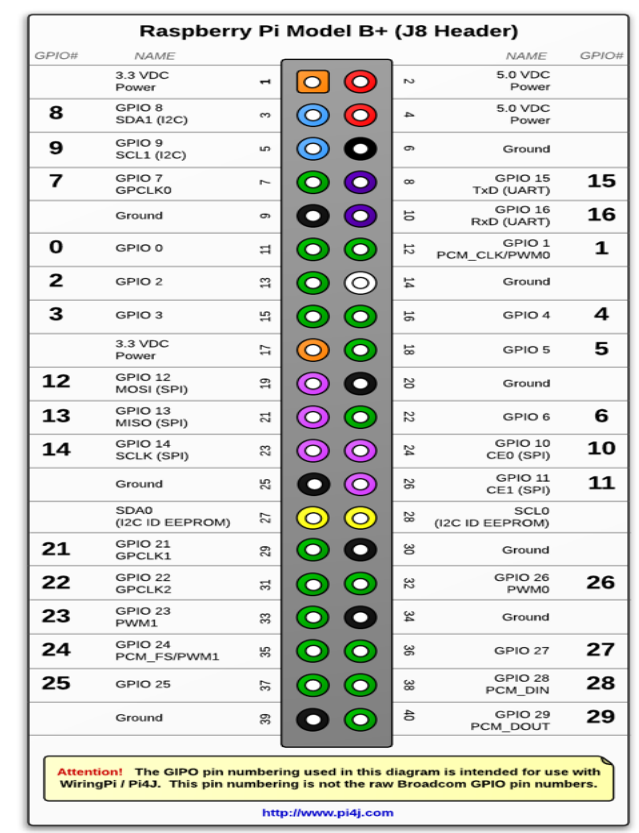

Gambar 5. Susunan Pin Raspberry Pi 3 Model B+ Menggunakan Pi4J (Pi4J, 2019)

\section{HASIL DAN PEMBAHASAN}

Bagian ini akan membahas tentang hasil implementasi dan pengujian sistem dari aplikasi dan sistem penyiraman berbasis IOT yang menggunakan metode pengembangan sistem adaptasi dari model Agile.

\subsection{Purwarupa sistem}

Halaman Utama sistem berguna untuk melihat persentase kelembaban tanah pada taman playground dan melakukan penyiraman secara langsung. Dari halaman utama, pengguna bisa berpindah ke halaman Jadwal Penyiraman. Implementasi halaman utama dan jadwal penyiraman dapat dilihat pada Gambar 6 .

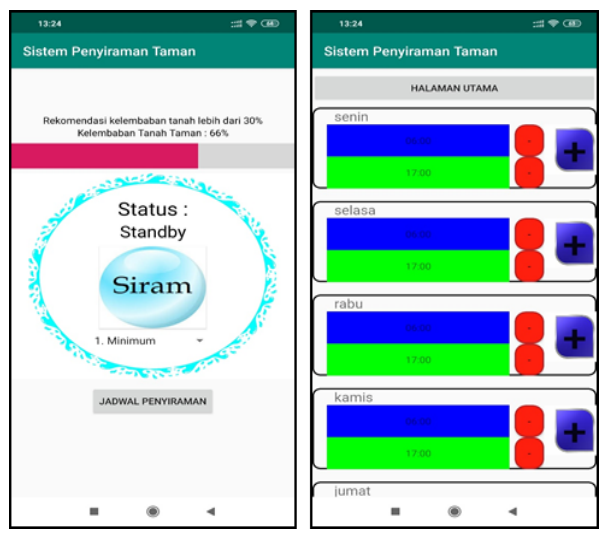

Gambar 6. Antarmuka halaman utama aplikasi

Pengguna dapat memberikan perintah melalui suara dengan menekan tombol "Siram" pada halaman utama kemudian menyebutkan "Siram" diikuti oleh intensitas penyiraman minimum, normal atau maksimum sesuai keinginan. Sistem juga akan 
memberikan notifikasi ke aplikasi jika kondisi tanah secara tiba-tiba berubah. Gambar 7 menunjukkan tampilan aplikasi ketika mode perintah suara dan notifikasi saat tanah menjadi kering.

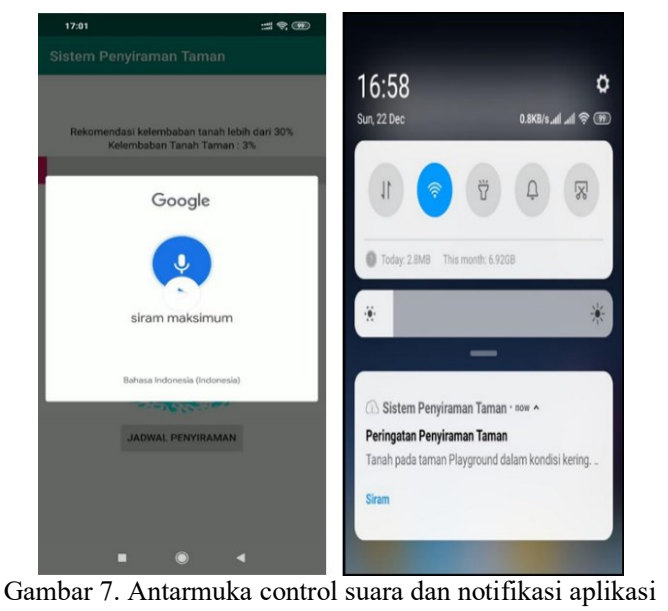

Dalam implementasi perangkat embedded ditambahkan perangkat Wifi portable sebagai fasilitas perangkat embedded agar bisa terhubung dengan jaringan Internet. Hasil implementasi perangkat embedded bisa dilihat pada Gambar 8 .

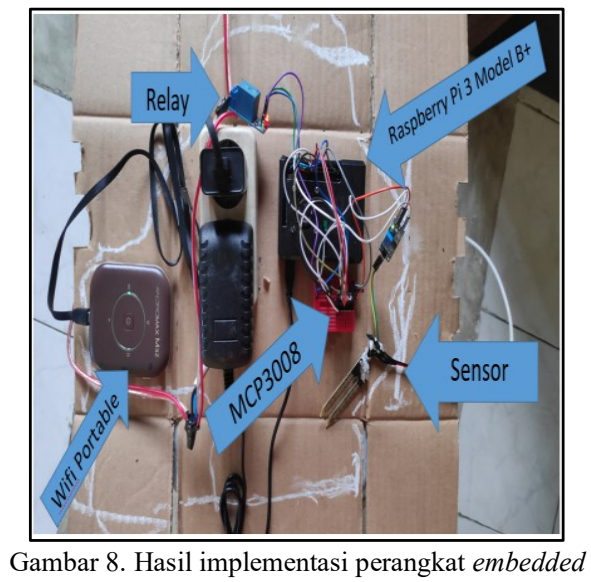

\subsection{Pengujian Sistem}

Blackbox Testing (pengujian fungsional) dan pengujian non-fungsional (pengujian pengujian usability) adalah salah satu metode yang dapat digunakan untuk pengujian sistem (Naik, 2008). Pengujian Blackbox dilakukan untuk mengetahui aplikasi yang dibuat sudah berjalan dengan baik sesuai dengan kebutuhan dan dapat digunakan oleh orang lain. Pengujian ini juga sekaligus bertujuan untuk menguji kompabilitas sistem terhadap beragamnya sistem operasi Android yang dipakai pada smartphone pengguna. Pengujian dilakukan oleh 5 penggguna yang merupakan pengelola dan perawat taman playground sekaligus pengurus inti yang ada di BUMDESMA. Pengujian dilakukan pada smartphone pengguna yang berbeda versi sistem operasi Android yaitu versi 5.0, versi 8.1, dan versi 9.0. Hasil pengujian pada kasus uji blackbox, diperoleh bahwa semua fitur di dalam aplikasi dapat berfungsi dengan baik sesuai dengan kebutuhan.

Untuk melihat tingkat kemudahan penggunaan aplikasi oleh staf BUMDESMA dilakukan pengujian usability. Pengujian usability dilakukan setelah pengujian blackbox selesai dilakukan dengan memberikan kuesioner yang dibagikan kepada ke 5 responden peserta pengujian blackbox. Nielsen menyatakan jumlah tersebut sudah mencukupi batas minimal untuk melakukan pengujian secara efektif dan efisien (Nielsen, 2020). Pengujian dijalankan dengan menggunakan metode SUS (System Usability Scale) dimana hasil dari pengujian usabilitas dapat dilihat pada Tabel 2.

\begin{tabular}{|c|c|c|}
\hline No & Kuesioner & Total \\
\hline 1 & $\begin{array}{l}\text { Saya akan menggunakan sistem } \\
\text { manajemen penyiraman taman } \\
\text { playground BUMDESMA } \\
\text { Kecamatan Ngantang untuk } \\
\text { menyiram taman playground } \\
\text { BUMDESMA Kecamatan Ngantang. }\end{array}$ & 20 \\
\hline 2 & $\begin{array}{l}\text { Saya menilai sistem ini menyediakan } \\
\text { alur yang kompleks. }\end{array}$ & 14 \\
\hline 3 & $\begin{array}{l}\text { Saya pikir aplikasi ini mudah } \\
\text { digunakan. }\end{array}$ & 14 \\
\hline 4 & $\begin{array}{l}\text { Saya merasa memerlukan dukungan } \\
\text { dari orang teknis untuk dapat } \\
\text { menggunakan aplikasi ini. }\end{array}$ & 16 \\
\hline 5 & $\begin{array}{l}\text { Saya menilai sistem ini menyediakan } \\
\text { fungsi yang saling berintegrasi } \\
\text { dengan baik. }\end{array}$ & 12 \\
\hline 6 & $\begin{array}{l}\text { Saya menilai sistem ini mengandung } \\
\text { banyak hal yang tidak konsisten. }\end{array}$ & 12 \\
\hline 7 & $\begin{array}{l}\text { Saya merasa banyak orang yang akan } \\
\text { dengan mudah menggunakan sistem } \\
\text { ini untuk melakukan penyiraman } \\
\text { pada taman playground. }\end{array}$ & 13 \\
\hline 8 & $\begin{array}{l}\text { Saya menilai sistem ini sangat rumit } \\
\text { untuk digunakan. }\end{array}$ & 14 \\
\hline 9 & $\begin{array}{l}\text { Saya merasa dapat menggunakan } \\
\text { sistem ini dengan baik dan percaya } \\
\text { diri. }\end{array}$ & 16 \\
\hline 10 & $\begin{array}{l}\text { Saya perlu belajar banyak hal } \\
\text { sebelum saya bisa menggunakan } \\
\text { aplikasi ini. }\end{array}$ & 13 \\
\hline \multicolumn{2}{|c|}{ Jumlah nilai total $* 2.5$} & 360 \\
\hline \multicolumn{2}{|c|}{ Rata-rata skor tiap responden } & 72 \\
\hline
\end{tabular}

Pernyataan yang ada di kuesioner diadopsi dari 10 pertanyaan SUS dengan pilihan jawaban berada pada nilai 0 - 4 yang dimulai dari sangat tidak setuju (STS), tidak setuju (TS), netral (N), setuju (S) serta sampai sangat setuju(SS) pada masing-masing pertanyaan. Untuk menghitung nilai SUS, nilai jawaban dari pertanyaan $1,3,5,7$, dan 9 dikurangi dengan 1. Untuk pertanyaan yang bersifat negatif pada nomor 2,4,6,8 dan 10 , nilai 5 dikurangi dengan nilai jawaban. Jumlah totalnya dan kaliakan dengan 2.5 untuk memperoleh nilai SUS rata-rata. (Lewis, 2009). Hasil dari pengujian ini menunjukan angka rata-rata pengujian yaitu 72 . Hal itu menunjukan bahwa sistem yang dikembangkan dapat diterima oleh pengguna dan mudah untuk digunakan (Sauro, 2011). 


\subsection{Kalkulasi Penghematan Biaya}

Pengujian efisiensi biaya dilakukan untuk mengetahui apakah sistem yang dibuat dapat menekan biaya pengeluaran BUMDESMA kecamatan Ngantang. Simulasi dilakukan pada pengujian ini untuk mengetahui perbandingan biaya pengeluaran untuk 3 bulan pertama antara penyiraman yang dilakukan oleh sistem dengan penyiraman oleh karyawan. Simulasi dilakukan dengan cara mengkalkulasi biaya pebuatan sistem dan biaya berjalan dari pengeluaran sistem selama 3 bulan dibandingkan dengan ongkos jasa perawatan taman yang berkisar 600.000 tiap bulan. Tabel 3 menunjukkan hasil simulasi perhitungan biaya.

\begin{tabular}{cccc}
\multicolumn{3}{c}{ Tabel 3. Hasil simulasi biaya } \\
\hline Pengeluaran & \multicolumn{2}{c}{ Jasa Taman } & \multicolumn{2}{c}{ Sistem Usulan } \\
\hline Bulan 0 & Rp. 600.000 & Rp. 1.100 .000 \\
Bulan 1 & Rp. 600.000 & Rp. 50.000 \\
Bulan 2 & Rp. 600.000 & Rp. 50.000 \\
\hline Total & Rp. 1.800 .000 & Rp. 1.200 .000 \\
\hline
\end{tabular}

\section{KESIMPULAN}

Berdasarkan pebangunan sistem manajemen penyiraman taman playground BUMDESMA Kecamatan Ngantang, diperoleh 14 daftar kebutuhan pada tahap analisis kebutuhan yang diantaranya adalah 6 kebutuhan perangkat lunak dan 8 kebutuhan perangkat keras sistem. Pengujian fungsional sistem menunjukkan semua fitur yang ada pada aplikasi dan sistem dapat berjalan dengan baik sesuai dengan kebutuhan di berbagai versi sistem operasi Android yaitu versi 5.0, versi 8.1, dan versi 9.0. Pengujian usability melalui SUS kuesioner yang telah diberikan kepada staf BUMDESMA mendapat angka 72, yang artinya bahwa aplikasi ini dapatditerima oleh calon pengguna. Pada hasil pengujian simulasi efisiensi biaya didapatkan hasil bahwa pengembangan sistem manajemen penyiraman taman playground biaya yang lebih mahal pada awal pengembanganya namun pada bulan kedua dan seterusnya penggunaan sistem dapat menekan biaya dibandingkan dengan penggunaan jasa karyawan dalam penyiraman taman playground BUMDESMA Kecamatan Ngantang.

\section{DAFTAR PUSTAKA}

ABRAHAMSSON, P., SALO, O., RONKAINEN, J. AND WARSTA, J., 2017. Agile software development methods: Review and analysis. arXiv preprint arXiv:1709.08439.

BRATA, K.C. AND LIANG, D., 2019. An effective approach to develop location-based augmented reality information support. International Journal of Electrical and Computer Engineering, 9(4), p.3060.

BRATA, K.C. AND BRATA, A.H., 2020. User experience improvement of japanese language mobile learning application through mental model and A/B testing. International Journal of Electrical and Computer Engineering, 10(3), p.2659.

JULIANTIKA, W. D. \& WICAKSONO, K. P., 2017. INTERVAL PENYIRAMAN TERHADAP PERTUMBUHAN DAN KUALITAS VISUAL TIGA JENIS TURFGRASS. Journal of Agricultural Science, pp. 76-84.

MATSUN, RAMADHANI, D. \& LESTARI, I., 2018. Pengembangan Bahan Ajar Listrik Magnet Berbasis Android Di Program Studi Pendidikan Fisika Ikip Pgri Pontianak. Jurnal Pendidikan Matematika dan IPA, IX(1), pp. 99-107.

MULYANTO, A. \& KUSHERMANTO, Y. B., 2017. Penerapan Teknologi RFID Modul RC522 Berbasis Raspberry Pi B+ Pada Sistem Absensi Siswa di SMK At-Taqwa Cabangbungin Kabupaten Bekasi. Jurnal Informatika SIMANTIK, I(2), pp. 26-31.

NAIK, K. DAN TRIPATHY, P. 2008. Software Testing and Quality Assurance Theory and Practice. Canada : Wiley

NIELSEN J. 2020. "Usability 101: introduction to usability“. [Online]. Tersedia di: http://www.nngroup.com/articles/u sability-101-introductionto-usability [Diakses, 10 Januari 2020]

PEREIRA, J.C. AND DE FSM RUSSO, R., 2018. Design thinking integrated in agile software development: A systematic literature review. Procedia computer science, 138, pp.775-782.

Pi4J., 2019. Pin Numbering - Raspberry Pi 3B+. [Online] Available at: https://pi4j.com/1.2/pins/model-3b-plusrev1.html [Accessed 27 Agustus 2019].

PUTRI, A. R., SUROSO \& NASRON, 2019. Perancangan Alat Penyiram Tanaman Otomatis pada Miniatur Greenhouse Berbasis IOT. Seminar Nasional Inovasi dan Aplikasi Teknologi di Industri 2019, pp. 155-159.

RAY, P.P., 2018. A survey on Internet of Things architectures. Journal of King Saud University-Computer and Information Sciences, 30(3), pp.291-319.

SAURO, JEFF. 2011. A practical guide to the system usability scale: Background, benchmarks \& best practices. Measuring Usability LLC.

SETHI, P. AND SARANGI, S.R., 2017. Internet of things: architectures, protocols, and applications. Journal of Electrical and Computer Engineering, 2017.

STOICA, M., GHILIC-MICU, B., MIRCEA, M. AND USCATU, C., 2016. Analyzing Agile Development-from Waterfall Style to Scrumban. Informatica Economica, 20(4). 
STATCOUNTER, 2019. Mobile Operating System Market Share in Indonesia - June 2019. [Online]

Available at: http://gs.statcounter.com/osmarket-share/mobile/indonesia

WIWIK, 2019. Laporan Wawancara Pengelola Playground Milik BUMDESMA Kecamatan Ngantang [Interview] (19 Februari 2019). 
Halaman ini sengaja dikosongkan 